\title{
Hubei Drum and Its Further Development from the Perspective of Intangible Cultural Heritage*
}

\author{
Laimin Zhang \\ Conservatory of Music \\ Huanggang Normal University \\ Huanggang, China
}

\begin{abstract}
Hubei drum is a folk talking-singing art, which is popular in Wuhan and the Eastern Hubei. It originated from Shandong drum and has a history of more than two hundred years. Its content truly reflects and represents the living conditions and vital interests of the vast majority of the working people, and conveys people's desire for brightness and happiness. In 2008, Hubei drum was included in the third batch of national intangible cultural heritage list. The most representative is the Siping Tune. It shows distinctive local characteristics and regional features in singing, performance and lyrics. The paper has discussed the development strategy of Hubei drum and its further development in order to attract academic and public attention.
\end{abstract}

Keywords-Hubei drum; artistic characteristics; living state; further development

\section{INTRODUCTION}

As a learner and scholar studying Chinese traditional music theory, the author has studied and paid attention to Hubei drum for many years, especially from the perspective of national intangible cultural heritage. The local government supports the drum and people love it. The author has seen its prosperity as well as difficulties confronting Hubei drum currently. With deep feelings, the author, both as a insider and outsider, has discussed and analyzed the further development of Hubei drum under the perspective of the non-material cultural heritage.

\section{HUBEI DRUM}

Since ancient times, Wuhan has been China's transport hub, connecting the north and the south, linking up the west and the east. With prosperous economic, Wuhan also gathers various talents, has lots of places of interests and rich music cultural heritages. People here can sing and dance. They love music. So far, folk talking-singing art is popular here. And Hubei drum is a representative.

Hubei drum, also known as "drum song" and "drumming and storytelling art" or "Beijing-accent Drum", is a talkingsinging art form. It has characteristics of vivid language, interesting and lively pattern and fast-paced rhythm. It is easily understood and attractive. It is a real "popular literature or art" and a "stranger". That Hubei drum is the typical "popular

*Science and Technology Research Project of Hubei Provincial Education Department; the project number: B2016235 literature or art" refers to that it likes other forms of talking singing, rooted in the folk and with a strong countryside flavor. But in the dark old society, it was regarded as "the inferior" that couldn't be regarded as an art. Its artists had low status, at the bottom of society. For a long time, it has no definite place for performance. In town it mostly was played in the teahouse or wine shop. In countryside, artists played it village to village, door to door. They knocked door and asked to perform. Circled a place and played a while to attractive audience. Then they sang one or two songs. Their income was very low, so it is hard to raise their family. They called Hubei drum "stranger" because it originated from Shandong drum. From the inheritance relation of drum artists, Shangdong drum has been taught in Hubei in the late Daoguang Year of Qing Dynasty. From the earliest artist Ding Haizhou (also named Ding Tieban), a Shandong drum artist, taking apprentices in Hubei, it is about nearly 200 years of history. In the late Qing Dynasty it formed two schools, the north school and the south school. People called the form of performance in north language with two crescent steel (iron or copper) plates and stick as playing instrument "the north drum music", and the form of performance in local language with wood plate and small drum as playing instrument "the south drum music". After long-term evolution of localization, it becomes a popular music with strong local characteristics. In 1950, artist Wang Mingyue proposed to define it as "Hubei drum". Quickly it was widely circulated in Hubei Province and the surrounding area.

Hubei drum artists passed their skills down to their apprentices through oral and mental instruction from generation to generation. The singing mainly reflects the suffering of labor people in old society, praises the truth, goodness and beauty and scourges the ugliness and falseness. At same time, it comprehensively shows folk and customs, practices, festivals, production, wedding and funeral, games and other aspects of life. Hubei drum truly reflected the living conditions of the broad masses. It fully represents the interests of the working people and their longing for happiness and brightness. It is a previous art rooted in the folk.

\section{ARTISTIC CHARACTERISTICS}

\section{A. Music Voice}

Hubei drum is a talking-singing art, similar to rap. Its music voice belongs to plate cavity structure. Siping Tune is a basic 
tune of its music voice. The entire tune is established on Fivevoice Zheng Mode. The plate-beating type generally is in good order and well arranged, and the lyric is sang together. There are two typical structures, two-section structure and foursection structure. The stops of the two-section structure separately are Re and Sol. The stop of the first section is relatively free. The music voice of the two-section structure generally can be seen in "cattle-raising model" in Hubei Drum (He Yuanzhi, Changjiang Literature and Art Publishing House, May 1982).

The stops of the four-section structure separately are Re, Sol, La (or Do) and Sol. The stop of the third section is relatively free. The last sentences of above two structures have a similar prolongation. It is Sol, La, Sol. The music voice of the four-section structure generally can be seen in "against waste" in Hubei Drum.

The music voice, rhythm, tonality and structure of Siping Diao are very similar with folk tune of "He Huo Qiang", "Gao Qiao Diao", "Caicha Diao" and "Cailian Chuan Diao" which are popular in the northeast of Hubei. Thus, after Shandong drum introduced in Hubei, its music voice and tune have been localized and changed in order to meet the appreciation habit of people there. It absorbed essence from local folk music, and formed a basic voice after refinement and processing.

The music voice of original Siping Diao is smooth and steady, full of life flavor. It is well expressed in a narrative and lyric way. In order to express different emotions and contents, drum artist has created a series of plate-structure music voice through changes of speed, beat and tone on the basis of the original one. It has greatly enriched the expression power of its music voice. Some works are of same beat and different speed and lyrics, such as, Slow Siping, Quick Siping, Sad Siping, Hanyong Siping, Wuzizhen Siping, Lanqiang Suiban, Sad Youban, Hua Qiang, Huixie Qiang and Banshan Diao. Some works are of one rhyme, such as, Siping Shuban, Kuailiu Shuiban and Jinban Jiqiang. Hubei drum has rich music voices and plate-beating styles. They are of different styles and functions. Hubei drum is a mature and typical plate-cavity structure art.

\section{B. Lyrics}

Hubei drum and the north drum are particular about the rhythm, beat and sentence style of lyrics. It requires rhyme in the compete lyric. It shall use words of same rhyme. The single sentences are flexible, but the couplet sentences shall be rhymed. It means the first, third and fifth sentences are flexible, and the second, fourth and sixth sentences are rhymed. Take lyrics of Sanyin for example: a hero looked around and saw a girl being bullied. He got angry and roared at the bad person. It is a typical sentence structure with tidy rhyme.

A works generally has seven or ten sentences in lyric which are basic sentence styles. Each sentence has three sections. The seven-sentence style is of two-two-three pattern. The tensentence style is of three-four-three pattern. In addition, it is allowed to add words for fluency.

\section{Performance}

In the performance, Hubei drum artists have created and perfected a unique set of performing skills, which can be summed up as four skills: hand, eye, body and step. The hand skill is to replace words with gesture language in order to express the content or emotions. For example, wave hands to call people or see people off; put a hand above eyes to look far; cover mouth and press close to ear to talk in a low voice. Thumb up to praise somebody. Extend a little figure to despise somebody. Clench fist to show one's determination. Open palm to show helplessness. In addition, they also use hands to point a direction or an object or to take a sword and spear. The eye skill is to express emotion and attitude. Eyes are the windows of the mind. The expression in the eyes is a significant performing means in art performance. Different eye expressions can express different emotions. It is no exception in Hubei drum. For example, gracile eyes mean flattery charm. Round eyes mean angry. Use white eyes and look askance and frown to show doubt, attaching importance and despise. In addition, it also can show the high and the low, the far and the near, the bright and the dark, the long and the short. Eye expressions coordinate with facial expressions to express joy, anger, sorrow and happiness, which can create unexpected artistic effect. The body skill, also known as body action, is to perform actions with body. Every action is standard. Open or close door, and get upstairs or downstairs. All actions are coordinated with dance and rhyme. They all take waist as center. Every action is natural and harmony. On the basis, entertainers shall relate skillful actions with the status of role, purpose of action and emotional conception, so as to give people a sense of reality. For example, a man generally straightens his waist, while a woman often walks with his hip slightly twisted; the old stoops slightly and a child bends knee; the strong lifts his chest and the weak shrinks his shoulders. The step skill means the step of entertainers on stage. The size change of steps shows different figures and behaviors. For example, a hero generally strides; a woman walks at small and uniform steps; a drunker stumbles and a scholar walks slowly. It also can express action of riding a horse, climbing a mountain or sitting on a sedan chair.

Drum artists have created and perfected a series of performing actions in practice. According to the need of each role, they summed up a word "twist". Twist one's body and immediately he/she will alter from one role into another role. Sometimes it is man or women, and sometimes it is a child or a grownup. Both body action and voice tone can be changed after a twisting action. It is to make the story and character connection more smooth and natural.

\section{LIVING STATE}

Hubei drum is affected by market economy and multiculture, and is gradually declining. The living state is not optimistic. Concretely it shows:

\section{A. Lack of Art Talents}

At present, the specialized teaching team of Hubei drum is weak. It lacks teaching places. The trained talents are expensively trained but serious lost because of the narrow 
living space. In the current environment, the young actors are not immature. It is difficult for them to achieve the artistic breakthrough. The old artists gradually leave the stage, resulting in to a temporary shortage and a lack of excellent talents. It is the key reason for the lack of development potential of Hubei drum.

\section{B. A Single Form of Performance}

The traditional performance of Hubei drum includes an actor, a drum and a stick. It performs through talking, singing and performing to develop the story plot and figures. Around the reform and opening-up, it has been ever performed by two and more actors and played with various musical instruments. But its lyrics and performing style still lacked expressive force, the spirit of the times and taste.

\section{Lack of Classical Works}

The traditional works of Hubei drum mainly are based on the masterpiece stories and "morality book". The lyrics are too old, which has a certain gap with contemporary people's aesthetic needs and aesthetic interest. It has no classical works with the flavor of the times. All of them affect the development of drum in the market.

\section{Further development}

Hubei drum is popular in Wuhan and the Eastern Hubei. There once appeared several excellent drum artists. In their efforts, some types were formed with strong local flavor. They have a great artistic vitality and vigor, and a very deep foundation of the masses. However, up to this day, Hubei drum, like other traditional folk art, is faced with unknown difficulties. As one of the few drum types in the south, it has attracted the attention of the government and the society. In 2008, Hubei drum has been listed as the third batch of intangible cultural heritage list in 2008. In 2012, more than ten students of the college of arts of Jianghan University have made a practical report about the living state and development strategies of Hubei drum in summer holidays in 2012. It has showed the artistic value and status in the eyes of the students.

In the new historical period, we should solve the following problems for the further development of Hubei drum.

Firstly, pay attention to personnel training. Talent is the key to the development of art. It is also a deep-seated cause of the difficulties faced by Hubei drum. That is the awareness of "responsibility rests where it belongs" of the cultural subject. Previously we attribute the difficult situation of folk music to the diversified impact of cultural appreciation and insufficient support of finance. But we ignore an important internal factor. That is the responsibility of the cultural subject. As the saying goes, "gold shines". This is a truth that never changes. Throughout the developing history of art, all single masters depend on their dinguses to open up market. The development of art relies on artists' charm to attract eyes of the public. There are too many such examples, such as, Zhao Benshan's Big Stage of Liu Laogen and Guo Degang's Deyun Crosstalk Association. Their performances are popular and often welcomed among the people. The cultural subject has become an artist as well as a wealthy owner. For another instance, grassroots artist $\mathrm{Gu}$ Yongzhang is famous for Henan Zhuizi. People call him "Blind Guo". He is highly favored for his superb artistic level and outstanding creative ability. A lot of departments invited him to perform. In 2010, a famous director Gu Changwei asked him to sing his good scripts in his film My Love. It has not only advertised himself but also carried forward the art. It has improved his economic condition. The awareness of "responsibility rests where it belongs" of the cultural subject is the inner power for the development of art. So, it is a pressing task to train the cultural subject of Hubei drum. In traditional performing art, a saying says: man protects play or play protects man. "Man protects play" means to promote and protect a type of play and make it popular by relying on the charm of talents.

Secondly, reform the art form. The traditional performing style of Hubei drum includes an actor, a drum and a stick. In order to achieve further development, we must carry out reform according to the aesthetic needs and tastes of the modern people. There are many successful reforms, which can be used for reference. For example: Datong Shulaibao is a plate-beating music which has become popular in recent years. Its successful reform has aroused a great impact in the national folk art circles. The reasons of its success lies in that: first, on basis of traditional performance, it has absorbed the elements of a variety of art forms, like cross talk, short sketch and opera. It has strong flavor of the times. Its language is humorous, and performance is full of affinity. It makes people think and arouses their sympathy. Relaxation, pleasure and sympathy are very necessary for modern people in art appreciation. Datong Shulaibao meets the need of the audience, so it is highly welcomed. Cross talk, short sketch and some other art forms have simple structure, fast rhyme and humorous language, so they are easily accepted and favored by people. According statistics, the most popular and welcomed art forms are cross talk and short sketch in the annual spring festival gala in CCTV. Their popularity was much more than other forms of art. The smart point of Datong Shulaibao is that it grafts the branches of cross talk and short sketch, and got a success. It can bring some enlightenment to the reform of Hubei drum. Second, use dialect flexibly. The commonness of Datong Shulaibao and Hubei drum is its strong regional flavor. Both of them use local dialect. It is difficult for outlanders to understand. Datong Shulaibao flexibly uses languages in different regions. For example, it uses mandarin when performed in CCTV and other areas. But, on the basis of not influencing the understanding of audiences, it still reserves Datong dialect. Fangbu Shengfang is the representative of Datong Shulaibao. It has reserved some dialect words, such as Ga Wawa, Nao Bu Cheng, Hu Nong Reng and Mai Jian Guo. The use of the dialect doesn't lose local characteristic but also make audience understand. It expands the group of audience and opens up the market. Hubei drum's performing market is only limited to the local place. Dialect is a main factor limiting its development. It is the key to make language reform in order to get a bigger stage and market. Third, "singing" of Hubei drum is real. Its tunes are from folk songs with lively rhythm and beautiful melody. It is rare and commendable in drum family. "Singing" of the north drum is from exaggeration of four tones in language. It is inferior to Hubei drum in melody. The beautiful melody and lively rhythm are the advantages of Hubei drum. We should 
keep them for the audience will love them. In addition, some points should be noted in lyrics and band formation. The style of lyrics should be tidy and rhythmic in order to be pleasant to listen to and convenient for memory. The lyrics should be understandable and simple. The band formation shouldn't be complicated. In addition to the actor, drum and stick, it can be coordinated with our traditional orchestras, like Yangqin, Pipa, Erhu and Sheng. It is unwise to use electric instruments, for it will destroy the beauty of tradition.

The third is the creation of excellent works. The excellent works means that works can reflect life of the times, have the mark of the times, can satire the bad and praise the good. The content can meet the aesthetic need of modern people. In slang "play protects man" means a good work can make an artist popular, and even save a type of play. Shiwuguan, a type of Kunqu, has save Kunqu on the edge of extinction. The further development of Hubei drum needs excellent works.

\section{CONCLUSION}

Contemporary China is experiencing the most extensive and profound social change in our country's history, and it is also carrying out the most magnificent and unique practice innovation in human history. This great practice will certainly provide a powerful impetus and vast space for artistic innovation. The local government departments and drum artists should seize the historical opportunities, focus on talent training and boldly borrow innovative performance form to create more excellent works. The three factors are indispensable and complementary. We have reason to believe that Hubei drum should take this valuable historical opportunity and get in-depth and long-term development in the current inheritance and protection.

\section{REFERENCES}

[1] He Yuanzhi. Hubei Drum. Hubei: Changjiang Literature and Art Publishing House, May 1982.

[2] Jiang Huiming: Jingyun Drum. Beijing: Culture and Art Publishing House, December 2013.

[3] Zhang Laimin: An Introduction to Chinese Folk Music. Shanghai: Shanghai Jiao Tong University Press, April 2016. 